\title{
Winning Isn't Everything: Corruption in Sumo Wrestling
}

\author{
By Mark Duggan and Steven D. LevitT*
}

There is a growing appreciation among economists of the need to better understand the role that corruption plays in real-world economies. Although some have argued that it can be welfare enhancing (Nathaniel Leff, 1964), most commentators believe that a willingness to accept bribes (or similar forms of corruption) in either the public or the private sector reduces economic efficiency (Andrei Shleifer and Robert W. Vishny, 1993). As a result, governments and firms often create incentives to motivate their employees to be honest (Gary S. Becker and George J. Stigler, 1974).

While it is generally agreed that corruption is widespread, there is little rigorous empirical research on the subject. Because of corruption's illicit nature, those who engage in corruption attempt not to leave a trail. As a consequence, much of the existing evidence on corruption is anecdotal in nature. More systematic empirical substantiation of corrupt practices is unlikely to appear in typical data sources. Rather, researchers must adopt nonstandard approaches in an attempt to ferret out indirect evidence of corruption.

To date, there have been only a handful of studies that attempt to systematically document the impact of corruption on economic outcomes. The first empirical study of corruption dates to 1846 when Quetelet documented that the height distribution among French males based on measurements taken at conscription was normally distributed except for a puzzling shortage of men measuring 1.57-1.597 meters

* Duggan: Department of Economics, University of Chicago, 1126 East 59th Street, Chicago, IL 60637, and National Bureau of Economic Research (e-mail: mduggan@midway .uchicago.edu); Levitt: American Bar Foundation and Department of Economics, University of Chicago, 1126 East 59th Street, Chicago, IL 60637 (e-mail: slevitt@midway .uchicago.edu). We would like to thank Gary Becker, Casey Mulligan, Andrei Shleifer, Stephen Stigler, Mark West, two anonymous referees, seminar participants, and especially Serguey Braguinsky for helpful comments. Kyung-Hong Park provided truly outstanding research assistance. Levitt gratefully acknowledges the research support of the National Science Foundation and Sloan Foundation. (roughly 5 feet 2 inches to 5 feet 3 inches) and an excess number of men below 1.57 meters. Not coincidentally, the minimum height for conscription into the Imperial army was 1.57 meters (Stephen Stigler, 1986). More recent empirical work on corruption includes Robert $\mathrm{H}$. Porter and J. Douglas Zona (1993), which finds evidence that construction companies collude when bidding for state highway contracts by meeting before the auction, designating a serious bidder, and having other cartel members submit correspondingly higher bids. R. Preston McAfee (1992) details a wide variety of bidrigging schemes. Paulo Mauro (1995) uses subjective indices of corruption across countries to demonstrate a correlation between corrupt governments and lower rates of economic growth, although the relationship may not be causal. Ray Fisman (2001) analyzes how stock prices of Indonesian firms fluctuate with changes in former Prime Minister Suharto's health status. Firms with close connections to Suharto, which presumably benefit from corruption within the regime, decline substantially more than other Indonesian firms when Suharto's health weakens. Whether the rents accruing to those close to Suharto are due to corruption or simply bad policy, however, is hard to determine. Rafael Di Tella and Ernesto Schargrodsky (2000) document that the prices paid for basic inputs at public hospitals in Buenos Aires fall by 10-20 percent after a corruption crackdown.

In this paper we look for corruption among Japan's elite sumo wrestlers. While acknowledging that sumo wrestling is not itself a subject of direct interest to economists, we believe that this case study nonetheless provides potentially valuable insights. First, if corrupt practices thrive here, one might suspect that no institution is safe. Sumo wrestling is the national sport of Japan, with a 2,000-year tradition and a focus on honor, ritual, and history that may be unparalleled in athletics. ${ }^{1}$ Moreover, Japan is generally

\footnotetext{
${ }^{1}$ See Mark West (1997) for an examination of the legal rules and informal norms that govern sumo wrestling in Japan.
} 
found to have relatively low rates of corruption in cross-country comparisons (Transparency International, 2000). ${ }^{2}$ Second, because of the simplicity of the institutional framework, it is easy to understand and model the incentives facing participants. Third, data to test for match rigging are readily available. While the exact techniques we utilize for studying corrupt behavior in sumo wrestling will require modification before being applied to more substantive applications, our analysis may nonetheless aid future researchers in that task.

The key institutional feature of sumo wrestling that makes it ripe for corruption is the existence of a sharp nonlinearity in the payoff function for competitors. A sumo tournament (basho) involves 66 wrestlers (rikishi) participating in 15 bouts each. A wrestler who achieves a winning record (eight wins or more, known as kachi-koshi) is guaranteed to rise up the official ranking (banzuke); a wrestler with a losing record (make-koshi) falls in the rankings. A wrestler's rank is a source of prestige, the basis for salary determination, and also influences the perks that he enjoys. ${ }^{3}$

Figure 1 demonstrates empirically the importance of an eighth win to a wrestler. The horizontal axis of the figure is the number of wins a wrestler achieves in a tournament; the vertical axis is the average change in rank as a consequence of the tournament. The change in rank is a positive function of the number of wins. With the exception of the eighth win, the relationship is nearly linear: each additional victory is worth approximately three spots in the rankings. The critical eighth win-which results in a substantial promotion in rank rather than a demotiongarners a wrestler approximately 11 spots in the ranking, or roughly four times the value of the

\footnotetext{
${ }^{2}$ Nevertheless, in recent years, sumo wrestling has been dogged by allegations of rigged matches, none of which have been substantiated. Officials from the Japanese Sumo Association dismiss these complaints as fabrications on the part of disgraced former wrestlers. Ultimately, despite years of allegations, no formal disciplinary actions have been taken towards any wrestler.

${ }^{3}$ For instance, the lowest-ranked wrestlers in the heya must rise early each morning to clean the building and prepare the food for the main meal of the day. When a wrestler reaches the rank of juryo, placing him among the top 66 sumo wrestlers in Japan, he no longer is required to do chores for other rikishi. Those in the top 40 with ranks of maegashira or better have their own servants.
}

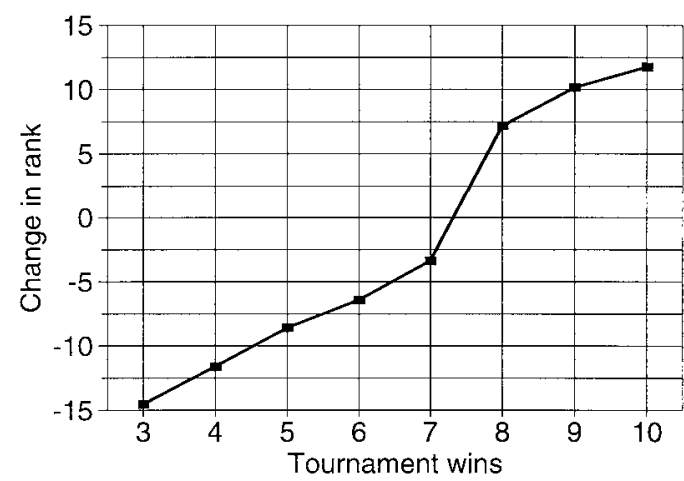

Figure 1. Payoff to Tournament Wins

typical victory. Consequently, a wrestler entering the final match of a tournament with a 7-7 record has far more to gain from a victory than an opponent with a record of, say, 8-6 has to lose. There will also be incentives for forwardlooking wrestlers to rig matches on earlier days of the tournament. ${ }^{4}$ According to our rough calculations, moving up a single spot in the rankings is worth on average approximately $\$ 3,000$ a year to a wrestler, so the potential gains to trade may be substantial if the wrestlers fix a match. ${ }^{5}$ Of course, no legally binding contract can be written.

In this paper, we examine more than a decade of data for Japan's sumo elite in search of evidence demonstrating or refuting claims of match rigging. We uncover overwhelming evidence that match rigging occurs in the final days of sumo tournaments. Wrestlers who are on the margin for attaining their eighth victory win far more often than would be expected. High winning percentages by themselves, however, are

\footnotetext{
${ }^{4}$ An earlier version of this paper, Duggan and Levitt (2001), derive a formal model of the incentives facing participants. For wrestlers on the bubble, the incentive to rig matches increases monotonically over the course of a tournament.

${ }^{5}$ Wrestlers ranked between fifth and tenth earn an annual income-including only official wages, bonuses, and prize money - of roughly $\$ 250,000$ per year. The fortieth-ranked wrestler earns approximately $\$ 170,000$. The seventiethranked wrestler receives only about $\$ 15,000$ per year (no official salary, just a small stipend to cover tournament expenses, some prize money, and room and board). All information on annual salaries are based on the authors' calculations and information provided in Mina Hall (1997). Unofficial sources of income such as endorsements would likely increase the disparity between the top and bottom wrestlers.
} 
far from conclusive proof of match rigging. Those wrestlers who are on the margin for achieving the eighth win may exert greater effort because their reward for winning is larger. We offer a number of pieces of evidence against this alternative hypothesis. First, whereas the wrestler who is on the margin for an eighth win is victorious with a surprisingly high frequency, the next time that those same two wrestlers face each other, it is the opponent who has an unusually high win percentage. ${ }^{6}$ This result suggests that at least part of the currency used in match rigging is promises of throwing future matches in return for taking a fall today. Second, win rates for wrestlers on the bubble vary in accordance with factors predicted by theory to support implicit collusion. For example, success rates for wrestlers on the bubble rise throughout the career (consistent with the development of reputation), but fall in the last year of a wrestler's career. Third, match rigging disappears during times of increased media scrutiny. Fourth, some wrestling stables (known as heya) appear to have worked out reciprocity agreements with other stables such that wrestlers from either stable do exceptionally well on the bubble against one another. ${ }^{7}$ Finally, wrestlers identified as "not corrupt" by two former sumo wrestlers who have alleged match rigging do no better in matches on the bubble than in typical matches, whereas those accused of being corrupt are extremely successful on the bubble. It is difficult to reconcile any of these findings with effort as the primary explanation.

The remainder of this paper is organized as follows. Section I introduces the data used in the analysis and presents the empirical evidence documenting the strong performance of wrestlers on the bubble. Section II attempts to distinguish between increased effort and match rigging as an explanation for the observed patterns in the data and also considers the way in which the market for rigged matches operates, e.g., how contracts are enforced, the use of cash payments versus promises of future thrown matches, and individuals versus stables as the level at which deals are brokered. Section III

\footnotetext{
${ }^{6}$ By the second subsequent meeting, the winning percentages revert back to the expected levels, suggesting that deals between individual wrestlers span only two matches.

${ }^{7}$ Wrestlers in the same stable do not wrestle each other.
}

concludes with a discussion of the broader economic implications of our analysis.

\section{Evidence of Strong Performance on the Bubble}

Our data set consists of almost every official sumo match that took place in the top rank (Sekitori) of Japanese sumo wrestling between January 1989 and January 2000. Six tournaments are held a year, with nearly 70 wrestlers per tournament, and 15 bouts per wrestler. Thus, our initial data set consists of over 64,000 wrestler-matches representing over 32,000 total bouts (since there are two wrestlers per bout). A small number of observations (less than 5 percent of the total data set) are discarded due to missing data, coding errors, or early withdrawal from the tournament due to injury. A total of 281 wrestlers appear in our data, with the average number of observations per wrestler in a randomly selected match equal to 554 , and a maximum of 990 . The average number of total matches between the same two wrestlers competing in a randomly selected match is 10 ; thus we often have many observations involving the same two wrestlers at different points in time.

For each observation, we know the identity of the two competitors, who wins, the month and year of the tournament, and the day of the match (tournaments last 15 days with one match per wrestler per day). For roughly 98 percent of the sample, we also know what wrestling stable the wrestlers belong to; information is missing for some wrestlers in the early part of our sample who had only a short stint in the top ranks.

We begin by looking at the distribution of wins across wrestlers at the end of tournaments. We expect that a disproportionate number of wrestlers should finish with eight wins because of the high payoff associated with the eighth win (see Figure 1). To the extent that wrestlers are rigging matches not only on the final day, but also in the days immediately preceding the end of the tournament, extra weight should also be observed on nine wins, as wrestlers who are close to the margin on days 13 or 14 may buy wins that ultimately were not needed to reach eight wins due to subsequent victories. Figure 2 presents a histogram of final wins for the 60,000 wrestler-tournament observations in which a wrestler completes exactly 15 matches. For purposes of comparison, we also present the 


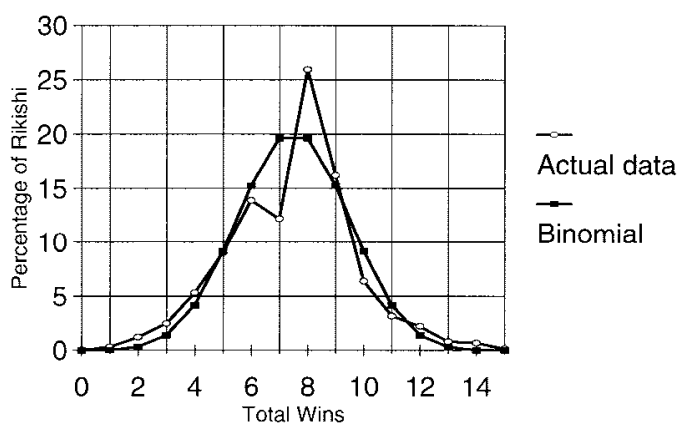

Figure 2. Wins in a Sumo Tournament (ACTUAL VS. BINOMIAL)

expected pattern of results assuming that all wrestlers are identical and that match outcomes are independently distributed.

Figure 2 provides clear visual evidence in support of the model's prediction. Approximately 26.0 percent of all wrestlers finish with exactly eight wins, compared to only 12.2 percent with seven wins. The binomial distribution predicts that these two outcomes should occur with an equal frequency of 19.6 percent. The null hypothesis that the probability of seven and eight wins is equal can be rejected at resounding levels of statistical significance. Nine victories also appears more often than would be expected. Although this distortion is far less pronounced visually, nine victories is significantly more likely than six (16.2 percent versus 13.9 percent).

Further evidence that wrestlers on the bubble win far more often than would be expected comes from estimating regressions of the general form

$$
\text { (1) } \begin{aligned}
\text { Win }_{i j t d}= & \beta \mathbf{B u b b l e} \\
& +\lambda_{i j t d}+\delta_{i t}+\boldsymbol{\epsilon}_{i j t d}
\end{aligned}
$$

where $i$ and $j$ represent the two wrestlers, $t$ corresponds to a particular tournament, and $d$ is the day of the tournament. The unit of observation is a wrestler-match. Bubble is a vector of indicator variables capturing whether wrestler $i$ or $j$ is on the margin for reaching eight wins in the bout in question. The Bubble variables are coded 1 if only the wrestler is on the margin, -1 if only the opponent is on the margin, and 0 if neither or both of the combatants are on the margin in the match. Rankdiff is the gap between the official ranking of wrestlers $i$ and $j$ entering tournament $t$. In some regressions, we include fixed effects for each wrestler and each opponent; in other specifications we include wrestler-opponent interactions. In all cases, we estimate linear probability models, with standard errors corrected to take into account the fact that a match is included in the data set twice-once for wrestler $i$ and once for wrestler $j$.

Table 1 reports the excess win percentages for wrestlers on the margin, by day, for the last five days of the tournament. On day 15, only wrestlers with exactly seven wins are on the margin; on day 14, wrestlers with either six or seven wins are on the margin, etc. The six columns correspond to different regression specifications. The even columns include the differences in ranks for the two wrestlers entering this tournament. The first two columns have no wrestler fixed effects; columns (3) and (4) include both wrestler and opponent fixed effects. The final two columns add wrestler-opponent interactions so that the identification comes only from deviations in this match relative to other matches involving the same two wrestlers.

The results in Table 1 are quite similar across specifications. ${ }^{8}$ Wrestlers on the bubble on day 15 are victorious roughly 25 percent more often than would be expected. Win percentages are elevated about 15 percent on day 14,11 percent on day 13 , and 5 percent on day 12 for wrestlers on the margin. There is no statistically significant evidence of elevated win rates for wrestlers on the bubble on day 11 . The pattern of coefficients is consistent with the hypothesis that the frequency of match rigging will rise as the tournament comes to a close. If all of the excess wins are due to rigging, then the results imply that on day 15 half of the bubble matches are crooked. For days 14, 13, and 12 respectively, the estimated percentage of rigged matches is roughly 28,22 , and 10 percent respectively.

\footnotetext{
${ }^{8}$ Adding the difference in current rank between wrestlers has little impact on the other coefficients in the regression. The difference in ranks is an important predictor of match outcomes when wrestler fixed effects are excluded from the model. The top-ranked wrestler facing an average wrestler would be expected to win about 70 percent of the time. Once we control for wrestler fixed effects, however, the explanatory power of the difference in ranks disappears.
} 
Table 1-Excess Win Percentages for Wrestlers on the Margin for Achieving an Eighth Win, BY DAY OF THE MATCH

\begin{tabular}{|c|c|c|c|c|c|c|}
\hline On the Margin on: & (1) & (2) & (3) & (4) & (5) & (6) \\
\hline Day 15 & $\begin{array}{c}0.244 \\
(0.019)\end{array}$ & $\begin{array}{c}0.249 \\
(0.019)\end{array}$ & $\begin{array}{c}0.249 \\
(0.018)\end{array}$ & $\begin{array}{c}0.255 \\
(0.019)\end{array}$ & $\begin{array}{c}0.260 \\
(0.022)\end{array}$ & $\begin{array}{c}0.264 \\
(0.022)\end{array}$ \\
\hline Day 14 & $\begin{array}{c}0.150 \\
(0.016)\end{array}$ & $\begin{array}{c}0.155 \\
(0.016)\end{array}$ & $\begin{array}{c}0.152 \\
(0.016)\end{array}$ & $\begin{array}{c}0.157 \\
(0.016)\end{array}$ & $\begin{array}{c}0.168 \\
(0.019)\end{array}$ & $\begin{array}{c}0.171 \\
(0.019)\end{array}$ \\
\hline Day 13 & $\begin{array}{c}0.096 \\
(0.016)\end{array}$ & $\begin{array}{c}0.107 \\
(0.016)\end{array}$ & $\begin{array}{c}0.110 \\
(0.016)\end{array}$ & $\begin{array}{c}0.118 \\
(0.016)\end{array}$ & $\begin{array}{c}0.116 \\
(0.019)\end{array}$ & $\begin{array}{c}0.125 \\
(0.019)\end{array}$ \\
\hline Day 12 & $\begin{array}{c}0.038 \\
(0.017)\end{array}$ & $\begin{array}{c}0.061 \\
(0.018)\end{array}$ & $\begin{array}{c}0.064 \\
(0.017)\end{array}$ & $\begin{array}{c}0.082 \\
(0.018)\end{array}$ & $\begin{array}{c}0.073 \\
(0.020)\end{array}$ & $\begin{array}{c}0.076 \\
(0.021)\end{array}$ \\
\hline Day 11 & $\begin{array}{c}0.000 \\
(0.018)\end{array}$ & $\begin{array}{c}0.018 \\
(0.018)\end{array}$ & $\begin{array}{c}0.015 \\
(0.018)\end{array}$ & $\begin{array}{c}0.025 \\
(0.018)\end{array}$ & $\begin{array}{c}0.010 \\
(0.021)\end{array}$ & $\begin{array}{c}0.012 \\
(0.021)\end{array}$ \\
\hline Rank difference & - & $\begin{array}{c}0.0053 \\
(0.0003)\end{array}$ & - & $\begin{array}{c}0.0020 \\
(0.0003)\end{array}$ & - & $\begin{array}{r}-0.0020 \\
(0.0004)\end{array}$ \\
\hline Constant & $\begin{array}{c}0.500 \\
(0.000)\end{array}$ & $\begin{array}{c}0.500 \\
(0.000)\end{array}$ & - & - & - & - \\
\hline$R^{2}$ & 0.008 & 0.018 & 0.030 & 0.031 & 0.0634 & 0.0653 \\
\hline Number of observations & 64,272 & 62,708 & 64,272 & 62,708 & 64,272 & 62,708 \\
\hline Wrestler and opponent fixed effects & No & No & Yes & Yes & Yes & Yes \\
\hline Wrestler-opponent interactions & No & No & No & No & Yes & Yes \\
\hline
\end{tabular}

Notes: The dependent variable in all regressions is an indicator variable corresponding to whether or not a wrestler wins the match. The unit of observation is a wrestler-match. Values reported in the table are coefficients associated with an indicator variable taking the value 1 if only the wrestler is on the margin for achieving eight wins, -1 if only the opponent is on the margin for achieving eight wins, and 0 otherwise. On day 15, only wrestlers with seven wins are on the margin. On day 14, wrestlers with six or seven wins are on the margin. On day 13, wrestlers with five, six, or seven wins are on the margin, and so on. The omitted category in all regressions is all wrestlers who are not on the margin for achieving eight wins, as well as wrestlers in matches in which both participants are on the margin for eight wins. When a full set of wrestler and opponent fixed effects are included, the constant is omitted. In all cases, standard errors are corrected to account for the fact that there are two observations per bout (one for each wrestler). The differences in the wrestler rank variable is the numerical rank order of the wrestler minus that of his opponent, based on official rankings published prior to each tournament. This variable is missing for part of our sample.

\section{Distinguishing Between Match Rigging and Effort}

The empirical results presented thus far are consistent with a model in which opponents throw matches to allow wrestlers on the margin to achieve an eighth victory. The results, however, are also consistent with a scenario in which effort is an important determinant of the match outcome, and wrestlers on the bubble, having more to gain from a win, exert greater effort. ${ }^{9}$ In this section, we present a wide variety

\footnotetext{
${ }^{9}$ The results are also consistent with a model in which wrestlers show altruism for one another, sacrificing their own outcomes to help an opponent who has more to gain. Given the nature of athletics and the nontrivial cost to the
}

of analyses that appear to confirm the corruption story and rule out effort as the explanation.

\section{A. What Characteristics Influence the Likelihood of Winning When on the Bubble?}

We begin by analyzing the personal and situational characteristics that influence the success rate of the wrestler on the bubble. One potentially important determinant of the frequency of match rigging is the probability that the collusive behavior will be detected. During our sample, there have been two periods in

wrestler of losing the match (roughly $\$ 10,000$ ), the altruism story strikes us as an unlikely explanation. 
which media attention has focused on match rigging. The first of these was in April and May of 1996. A former sumo wrestler who had become a stable-master came forward with allegations of match rigging. At the same time, another former wrestler also came forward to decry rigged matches. Ironically, both of these men died a few weeks later, just hours apart, in the same hospital. This fueled speculation among the media of foul play, although a subsequent police investigation revealed no evidence for this. The second period of media scrutiny took place in late 1999-early 2000. A former sumo wrestler named Itai raised allegations of match rigging that were widely covered by the media, even in the United States. The three tournaments in our sample that are most likely to be affected by the media attention are those held in May 1996, November 1999, and January 2000.

The literature on repeated-play games (e.g., Drew Fudenberg and Jean Tirole, 1991) suggests that the ability to sustain collusion should be positively related to the frequency with which two wrestlers expect to meet in the future since more future meetings imply the availability of more severe punishments for wrestlers who do not cooperate. Empirically, we proxy the expected frequency of future matches using two variables: (1) the number of meetings between the two wrestlers that took place in the preceding year, and (2) whether the wrestler is in the last year of his career. Although the precise ending of a wrestler's career is not known in advance to the participants, it is likely that signals of retirement are available (e.g., declining performance, injuries, etc.). ${ }^{10}$ If it takes time to establish a reputation as a wrestler who is willing to collude and who can be trusted, then one might predict that the longer a wrestler has been active in the top ranks of sumo, the better he will do when he is on the bubble, and also, the worse he will perform when the opponent is on the bubble.

Because there are a series of monetary prizes given to wrestlers who have good records in a

\footnotetext{
${ }^{10}$ In order to minimize endogeneity, we exclude the very last tournament of a wrestler's career. It is possible that a loss on the bubble may drop the wrestler out of the top level of wrestlers, inducing retirement. Including the last tournament of a wrestler's career slightly increased the magnitude and statistical significance of the coefficient.
}

given tournament, wrestlers in the running for such prizes are unlikely to be willing to throw matches. ${ }^{11}$ The overall tournament champion wins $\$ 100,000$; the juryo champion wins $\$ 20,000$. In addition, $\$ 20,000$ awards for "fighting spirit" and "outstanding technique." In order to win those prizes, wrestlers must compile very strong records. The potential value of a victory for a wrestler in the running for such prizes is likely to be at least as great as the value to a wrestler on the margin for an eighth win.

A final determinant of match rigging that we consider is the possibility of coordinated match rigging among stables of wrestlers. The lives of sumo wrestlers center around the stable with which they are associated. Stable-masters exert a tremendous influence over both the wrestling career of wrestlers and their lives more generally. ${ }^{12}$ Given the important role of the stable, and the fact that stable-masters benefit from having highly ranked wrestlers, it would not be surprising if corruption were coordinated at the stable level. For example, stables might have collective reputations, with stable-masters enforcing punishments on wrestlers who pursue their individual best interests at the expense of the stable. Some stable-masters, on the other hand, may not condone match rigging because of ethical concerns or risk aversion.

We empirically examine one particular form of stable-level collusion: the presence of reciprocity agreements across stables. If such deals existed, one would expect both that wrestlers from stable $A$ will have very high win rates when on the bubble facing wrestlers from stable $B$, and vice versa. ${ }^{13}$ It is difficult to tell an alternative story that would account for such a pattern in the data. For instance, if effort is the

\footnotetext{
${ }^{11}$ Although we do not directly observe which wrestlers might be under consideration for these prizes, having one of the five best records (plus ties) up until that point in the tournament is an excellent predictor. Wrestlers with one of the five best records in the tournament entering days 13, 14, or 15 win a prize 50 percent of the time. Less than five percent of wrestlers with records outside the top five on days $13-15$ eventually win a prize.

${ }^{12}$ For instance, it is expected that the foremost sumo wrestler in a stable will marry the daughter of the stable-master.

${ }^{13}$ The variable we use to test this empirically is the overall win rate for wrestlers on the bubble in matches involving both a wrestler from stable $A$ and a wrestler from stable $B$ (excluding the current match). This variable reflects both stable $A$ 's success on the bubble against stable $B$ and stable $B$ 's success against stable $A$.
} 
story, then stables with wrestlers capable of exerting particularly high effort when they need a win might also be expected to have wrestlers who rise to the occasion when faced with the opportunity to beat a very motivated opponent, leading to a zero or negative correlation. Similarly, if one stable has developed specific techniques that provide it with an advantage over a particular stable, success rates on the bubble will again be negatively related.

These various hypotheses are tested in Table 2. Because our interest is in how these factors influence success on the bubble, the table reports only the coefficients on the interactions between these various factors and the outcome of bubble matches, i.e., any incremental impact that these factors have on bubble matches above and beyond their impact in nonbubble matches. Also included in the specifications, but not shown in the table, are the main effects. Column (1) is the baseline specification. Column (2) adds both wrestler and opponent fixed effects. Column (3) also includes wrestler-opponent interactions. The results are generally quite similar across the three columns of the table.

The top row of the table is the main effect of a wrestler being on the bubble, which leads to an excess win likelihood of roughly 12-16 percentage points. In those tournaments with a high level of media scrutiny, however, these excess wins completely disappear. ${ }^{14}$ In two of the three specifications, the performance of wrestlers on the bubble in high and low media scrutiny tournaments is statistically significant at the 0.05 level. In none of the three columns can one reject the null hypothesis that wrestlers on the bubble in high-scrutiny tournaments do any better than chance. In the words of Supreme Court Justice Louis D. Brandeis, "Sunlight is said to be the best disinfectant."15

When the opponent is in the running for winning one of the special prizes awarded, any benefit of being on the bubble also disappears. This result is consistent with opponents in the running for prizes being unwilling to throw a match.

The variables designed to capture factors in-

\footnotetext{
${ }^{14}$ To calculate the overall excess win percent for a wrestler on the bubble in a period of high media scrutiny, the coefficients in rows 1 and 2 are added together.

${ }^{15}$ We thank an anonymous referee for bringing this very appropriate quote to our attention.
}

TABLE 2-DETERMinANTS OF EXCESS Win LiKELIHOODS FOR WRESTLERS ON THE BUBbLE

\begin{tabular}{lccc}
\hline \hline Variable & $(1)$ & $(2)$ & $(3)$ \\
\hline Wrestler on bubble & $\begin{array}{c}0.126 \\
(0.026)\end{array}$ & $\begin{array}{c}0.117 \\
(0.026)\end{array}$ & $\begin{array}{c}0.155 \\
(0.029)\end{array}$
\end{tabular}

Wrestler on bubble

interacted with:

$\begin{array}{lccc}\text { High media } & -0.188 & -0.177 & -0.146 \\ \quad \text { scrutiny } & (0.071) & (0.071) & (0.080) \\ & & & \\ \text { Opponent in } & -0.149 & -0.129 & -0.156 \\ \quad \text { running for a } & (0.047) & (0.046) & (0.052)\end{array}$

prize this

tournament

Number of

meetings

$-0.0048$

$-0.0031$

$-0.0024$

between two

(0.0082)

(0.0081)

(0.0096)

opponents in

the last year

Wrestler on

bubble

in his last year

of competing

Years in sumo for wrestler on

bubble

Winning

percentage in

other bubble

matches

between these

two stables

\begin{tabular}{lccc}
$R^{2}$ & 0.016 & 0.074 & 0.246 \\
$\begin{array}{l}\text { Wrestler and } \\
\text { opponent fixed } \\
\text { effects? }\end{array}$ & No & Yes & Yes \\
$\begin{array}{c}\text { Wrestler-opponent } \\
\text { interactions? }\end{array}$ & No & No & Yes \\
\hline
\end{tabular}

Notes: The dependent variable in all three regressions is an indicator variable corresponding to whether or not a wrestler wins the match. In addition to the listed interaction terms, all main effects are also included in the specifications. Wrestler on bubble is an indicator variable that equals $1(-1)$ if the wrestler (opponent) is on the bubble on days 13,14 , or 15 (record of $7-7,7-6,6-7,7-5,6-6$, or $5-7$ ) but the opponent (wrestler) is not, and 0 otherwise. Matches from 1989, the first year of our sample, are excluded because the variable for the number of matches between the two wrestlers in the previous year cannot be computed. Observations where stables are unknown or no two wrestlers from the stables ever meet on the bubble in our data set are also excluded from the sample. The number of observations is consequently 42,788. Standard errors are corrected to account for the fact that there are two observations per bout (one for each wrestler). 
fluencing implicit collusion achieve mixed results. The number of matches between two wrestlers in the preceding year has an unexpected negative impact on a wrestler's likelihood of winning a match on the bubble, although the coefficient is substantively small and carries a $t$-statistic of far less than 1 in all of the specifications. Wrestlers in the last year of their career do slightly worse than expected on the bubble, although again the result is not statistically significant. With the exception of the last year, however, success on the bubble increases over the career. A five-year veteran is about 4 percentage points (off a baseline of 13 percentage points) more likely to win on the bubble than a rookie. This last result is consistent with the importance of developing a reputation.

Finally, the bottom row of coefficients in Table 2 measures the extent to which a wrestler's success on the bubble today is influenced by overall success rates (excluding this match) when wrestlers from that stable meet wrestlers from the opponent's stable and one of the wrestlers is on the bubble. ${ }^{16}$ The coefficient is strongly positive and statistically significant. As noted above, that result that is difficult to reconcile with any hypothesis other than stablecoordinated collusion. Moreover, the size of the coefficient is large: for each 10-percentagepoint increase in success in other bubble matches between these two stables, the wrestler on the bubble is 3 percentage points more likely to win today, controlling for other factors.

\section{B. What Happens When Wrestlers Meet Again in the Future?}

If collusion is the reason that wrestlers on the bubble perform well, then the opponent must be compensated in some way for losing the match. It is possible that such payments are made in cash, or in promises to return the favor in the future. The likelihood that two wrestlers will meet again soon is high: in our data 74 percent of the wrestlers who meet when one is on the margin for eight wins will face one another again within a year.

\footnotetext{
${ }^{16}$ Because wrestlers do not change stables over the course of their careers, there is no usable variation in this variable when wrestler-opponent interactions are included in column (3).
}

Table 3 explores the pattern of match outcomes over time for wrestlers who meet when one is on the margin. The even columns include wrestler-opponent interactions so identification of the parameters comes only from variation in outcomes involving the same two opponents; the odd columns do not. The regression specifications include indicator variables categorizing the timing of the meetings between two wrestlers relative to the match where one wrestler is on the bubble. The omitted category is matches preceding a bubble meeting by at least three matches. ${ }^{17}$

Focusing first on columns (1) and (2), which correspond to all meetings on the bubble, there are no systematic differences in outcomes in the two matches preceding the match on the bubble, as reflected in the statistically insignificant coefficients in the top row. When the wrestler is on the bubble (second row), he is much more likely to win, consistent with the earlier tables. The parameter of greatest interest is the negative coefficient for the first meeting between the two wrestlers after the match in which the wrestler is on the bubble. The wrestler who was on the margin in the last meeting is approximately seven percent less likely to win than would otherwise be predicted. This finding is consistent with part of the compensation for throwing a match being the promise of the opponent returning the favor in the next meeting. There is no evidence that any return of favors extends beyond the next match, as two and three matches out the winning percentages return to normal.

The final four columns of Table 3 replicate the first two columns, except that the sample is divided into cases where the wrestler wins when on the margin versus instances when the wrestler loses when on the margin. ${ }^{18}$ One would not expect a wrestler to intentionally lose in future meetings to an opponent who does not throw the match on the margin. Thus, breaking down the

\footnotetext{
${ }^{17} \mathrm{We}$ have experimented with other groupings of matches, for instance allowing a different coefficient for matches preceding/following the bubble match by more than three meetings. The parameters of interest are not sensitive to alternative specifications.

${ }^{18}$ In columns (3)-(6), the actual matches taking place on the bubble are excluded from the regression since there is no variation. In columns (3) and (4), all bubble matches are won by the wrestler on the bubble; in columns (5) and (6), no matches are won by the wrestler on the bubble.
} 
Table 3-Win Percentages in Preceding and Subsequent Matches

(For Two Wrestlers Who Meet When One is on the Margin in the Final Three Days of a Tournament)

\begin{tabular}{|c|c|c|c|c|c|c|}
\hline \multirow[b]{2}{*}{ Variable } & \multicolumn{2}{|c|}{$\begin{array}{l}\text { All Matches on the } \\
\text { Margin }\end{array}$} & \multicolumn{2}{|c|}{$\begin{array}{l}\text { Only Matches in } \\
\text { Which the Wrestler on } \\
\text { the Margin Wins }\end{array}$} & \multicolumn{2}{|c|}{$\begin{array}{l}\text { Only Matches in } \\
\text { Which the Wrestler on } \\
\text { the Margin Loses }\end{array}$} \\
\hline & (1) & (2) & (3) & (4) & (5) & (6) \\
\hline $\begin{array}{l}\text { One or two matches prior to the } \\
\text { bubble match }\end{array}$ & $\begin{array}{c}-0.002 \\
(0.009)\end{array}$ & $\begin{array}{c}0.005 \\
(0.012)\end{array}$ & $\begin{array}{c}0.020 \\
(0.011)\end{array}$ & $\begin{array}{c}0.019 \\
(0.017)\end{array}$ & $\begin{array}{c}-0.041 \\
(0.016)\end{array}$ & $\begin{array}{c}-0.035 \\
(0.022)\end{array}$ \\
\hline Bubble match & $\begin{array}{c}0.151 \\
(0.010)\end{array}$ & $\begin{array}{c}0.164 \\
(0.014)\end{array}$ & - & - & - & - \\
\hline First meeting after bubble match & $\begin{array}{c}-0.073 \\
(0.011)\end{array}$ & $\begin{array}{r}-0.062 \\
(0.015)\end{array}$ & $\begin{array}{c}-0.082 \\
(0.015)\end{array}$ & $\begin{array}{c}-0.079 \\
(0.020)\end{array}$ & $\begin{array}{c}-0.056 \\
(0.020)\end{array}$ & $\begin{array}{r}-0.040 \\
(0.027)\end{array}$ \\
\hline Second meeting after bubble match & $\begin{array}{c}-0.002 \\
(0.013)\end{array}$ & $\begin{array}{c}0.005 \\
(0.016)\end{array}$ & $\begin{array}{c}0.031 \\
(0.017)\end{array}$ & $\begin{array}{c}0.028 \\
(0.022)\end{array}$ & $\begin{array}{c}-0.061 \\
(0.023)\end{array}$ & $\begin{array}{r}-0.039 \\
(0.030)\end{array}$ \\
\hline $\begin{array}{l}\text { Three or more meetings after } \\
\text { bubble match }\end{array}$ & $\begin{array}{r}-0.010 \\
(0.006)\end{array}$ & $\begin{array}{c}0.012 \\
(0.011)\end{array}$ & $\begin{array}{c}0.013 \\
(0.007)\end{array}$ & $\begin{array}{c}0.022 \\
(0.014)\end{array}$ & $\begin{array}{c}-0.045 \\
(0.008)\end{array}$ & $\begin{array}{c}-0.013 \\
(0.017)\end{array}$ \\
\hline Constant & $\begin{array}{c}0.500 \\
(0.000)\end{array}$ & - & $\begin{array}{c}0.500 \\
(0.000)\end{array}$ & - & $\begin{array}{c}0.500 \\
(0.000)\end{array}$ & - \\
\hline Wrestler-opponent interactions? & No & Yes & No & Yes & No & Yes \\
\hline$R^{2}$ & 0.008 & 0.271 & 0.002 & 0.279 & 0.002 & 0.279 \\
\hline
\end{tabular}

Notes: Entries in the table are regression estimates of the outcomes of matches between, after, and contemporaneous with these two wrestlers meeting when one wrestler is on the margin for achieving eight wins on the last three days of the tournament. The dependent variable in all regressions is an indicator variable for whether the wrestler wins a match. The unit of observation is a wrestler match. The first two columns correspond to all wrestlers who meet when one is on the margin. In columns (3) and (4), the coefficients reported correspond only to those cases where the wrestler on the bubble wins the match. Columns (5) and (6) report coefficients only for those wrestlers on the bubble who lose the match. Columns (3) and (5) are estimated jointly, as are columns (4) and (6). Except for columns (1) and (2), bubble matches are excluded from the regressions. The excluded category in all regressions are matches occurring more than two matches prior to a bubble match and not falling into any of the other categories named. When a full set of wrestler and opponent fixed effects are included, the constant is omitted. In all cases, standard errors are corrected to account for the fact that there are two observations per bout (one for each wrestler). Number of observations is equal to 64,273.

data in this way provides a natural test of the hypothesis that the poor performance in the next match is due to a deferred payoff to an opponent who threw a match. The data provide clear support for the collusion hypothesis. Wrestlers who win on the bubble tend to do slightly better than expected leading up to the bubble match, then do much worse in the next meeting with the same opponent. Relative to the surrounding matches, the first post-bubble match sees the wrestler losing approximately 10 percentage points more frequently than would be expected (i.e., row 3 minus row 1).

The pattern for wrestlers who lose to the opponent when on the margin for achieving eight wins is very different. In the matches just prior to the bubble match, the wrestler is slightly underperforming. This continues unaffected through the post-bubble matches as well. Unlike columns (1)-
(4), there is no downward spike in wins following the bubble match. The finding that winners on the bubble fare badly the next time they face the same opponent, but losers do not, is consistent with the match-rigging hypothesis, but not with an effort story. If increased effort is responsible for strong performances in matches on the margin, there is no reason to expect systematic underperformance the next time the two wrestlers meet, and certainly

\footnotetext{
${ }^{19}$ When two wrestlers meet and both are on the bubble, there is similarly no evidence that the wrestler who wins fares more poorly the next time the two wrestlers meet. This is consistent with no match rigging occurring when both wrestlers are on the bubble, as predicted by the model.

More generally, there is no evidence of negative serial correlation in match outcomes. When multiple lags of past match outcomes between the two wrestlers are added to the specifications, the coefficients are positive.
} 
not exclusively among those who won on the bubble. $^{19}$

The payment-in-kind story suggested by the results above is unlikely to be the only form of compensation for wrestlers who throw matches. Based on Table 3, roughly two-thirds of the excess wins garnered on the bubble are returned the next time the two wrestlers meet. This price-two-thirds of a match down the road in return for throwing a match today-is too low to represent the only form of payment. When rumors circulate about match rigging in sumo, they often suggest the presence of cash transfers, although we are able to provide no evidence about this channel.

\section{Do the Data Confirm Public Allegations of Cheating by Sumo Insiders?}

Two former sumo wrestlers have made public the names of 29 wrestlers who they allege to be corrupt and 14 wrestlers who they claim refuse to rig matches (Keisuke Itai, 2000; Onaruto, 2000; Shukan Post, 2000). ${ }^{20}$ In this section, we investigate whether the performance on the bubble of these two groups of wrestlers systematically differs. If strong performance on the bubble is due to match rigging and the allegations are true, then one would expect the corrupt wrestlers to do extremely well on the bubble, whereas the honest wrestlers would do no better in bubble matches than on any other match.

To test this hypothesis, we estimate a regression identical to equation (1), but including a full set of interactions between whether a match is on the bubble and the classification of each wrestler and his opponent as either "corrupt," "clean," or "status unknown." Only 43 of the 281 wrestlers (15 percent) in our sample are specifically identified as either corrupt or clean. The remainder are classified as status unknown. The whistle-blowers were more likely to identify prominent wrestlers with long careers, however, so over 60 percent of the matches in our sample involve at least one wrestler identified by name as either clean or corrupt.

\footnotetext{
${ }^{20}$ The books that we cite are published only in Japanese. We thank Serguey Braguinsky both for bringing the existence of this information to our attention and for translating the relevant material for us.
}

Table 4 reports the results of the estimation. All of the coefficients in the table come from a single regression. The values in the table represent excess win percentages on the bubble, i.e., how much better a wrestler does when on the bubble relative to matches in which neither wrestler is on the bubble. The columns of the table identify the status of the wrestler on the bubble-the wrestler who wants to buy a victory. The rows correspond to the status of the opponent of the wrestler on the bubble-the wrestler who might want to sell a win. When two wrestlers identified as corrupt meet on the bubble, the one who needs the victory is 26 percentage points more likely to win the match than if those two wrestlers met with neither on the bubble. This excess win percentage is highly statistically significant. When a corrupt wrestler meets a wrestler classified as "status unknown," the results are very similar. Win percentages for the wrestler needing the victory when both wrestlers are classified as "status unknown" are also highly elevated (18.1 percentage points higher), but not quite as extreme. In stark contrast, none of the five coefficients involving wrestlers identified as clean are statistically significant from zero. This implies that the outcomes of bubble matches involving a clean wrestler are no different than the results when the same two wrestlers meet, but neither is on the bubble. This result holds true regardless of whether the clean wrestler is himself on the bubble or facing a wrestler who is on the bubble. Thus, Table 4 provides strong confirmation not only of the claim that elevated win percentages on the bubble are due to match rigging, but also that the allegations made by the two sumo insiders appear to be truthful. Moreover, it appears that most of the wrestlers not specifically named by the whistle-blowers are corrupt, since their outcomes differ only slightly from those wrestlers named as corrupt.

\section{Conclusion}

This paper provides strong statistical analysis documenting match rigging in sumo wrestling. The incentive structure of promotion leads to gains from trade between wrestlers on the margin for achieving a winning record and their opponents. We show that wrestlers win a disproportionate share of the matches when they are on the margin. Increased effort cannot 
Table 4-Excess Win Percentages on the Bubble for Wrestlers Labeled by Sumo INSIDERS AS "CORRUPT" OR "ClEAN"

\begin{tabular}{ll|cc|c}
\hline \hline & & \multicolumn{2}{c}{ Wrestler on the Bubble Is Identified as: } \\
\cline { 3 - 5 } & & Corrupt & Status Unknown & \multicolumn{1}{c}{ Clean } \\
\hline & Corrupt & 0.260 & 0.270 & -0.010 \\
Opponent of & & $(0.037)$ & $(0.021)$ & $(0.038)$ \\
wrestler on the & Status & 0.271 & 0.181 & 0.041 \\
bubble is & unknown & $(0.021)$ & $(0.019)$ & $(0.031)$ \\
identified as: & Clean & 0.036 & -0.033 & 0.022 \\
& & $(0.027)$ & $(0.035)$ & $(0.074)$ \\
\hline
\end{tabular}

Notes: Entries in the table are coefficients from a regression with full set of interactions between whether a match is on the bubble and the classification of a wrestler and his opponent as clean, corrupt, or status unknown by two sumo insiders (Itai, 2000; Onaruto, 2000; Shukan Post, 2000). The regression is identical to equation (1) in the text, except for the inclusion of the aforementioned interactions. Twenty-nine wrestlers are categorized as corrupt, 14 are classified as clean. The remainder of wrestlers are not specifically named and are categorized as status unknown. Standard errors are corrected to take into account that there are two observations per bout (one for each wrestler). Number of observations is equal to 64,273.

explain the findings. Match rigging disappears in times of increased media scrutiny. Wrestlers who are victorious when on the bubble lose more frequently than would be expected the next time they meet that opponent, suggesting that part of the payment for throwing a match is future payment in-kind. Reciprocity agreements between stables of wrestlers appear to exist, suggesting that collusive behavior is not carried out solely by individual actors. Allegations by sumo insiders are demonstrated to be verified in our data.

While sumo wrestling per se is not of direct interest to economists, the case study that it provides is potentially of usefulness to the economic analysis of corruption. Anecdotal allegations of corrupt practices among sumo wrestlers have occasionally surfaced, but have been dismissed as impossible to substantiate. In this paper, we demonstrate that the combination of a clear understanding of the incentives facing participants combined with creative uses of data can reveal overwhelming statistical evidence of corruption. Details of the corrupt practices, the data sources, and the telltale patterns in the data will all vary from one application to the next. Nonetheless, the success of our study in documenting the predicted patterns of corruption in one context raises the hope that parallel studies with more substantive economic focus may yield similar results.

Moreover, our analysis provides insight into how to combat corruption. First, the match rigging we identify can be directly linked to the artificially imposed nonlinearity in incentives for wrestlers who achieve a winning record. ${ }^{21}$ Removing this distortion to incentives would eliminate the benefits of corruption. Second, match rigging appears to be sensitive to the costs of detection. Increased media scrutiny alone is sufficient to eliminate the collusive behavior. Presumably, other approaches to raising the expected punishment would likewise be effective. Third, at least in the sumo context, insiders appear to have good information about who is corrupt. Providing strong incentives for whistle-blowers, particularly when such accusations can be corroborated by objective data analysis, may prove effective in restraining corrupt behavior.

While perhaps beyond the scope of this paper, a question of interest is why those in charge of the sumo wrestling have not attempted to eliminate corruption, either by eliminating the nonlinearity or by increasing expected punishments. A partial answer is that there are barriers to entry for a second sumo league, so the competitive pressure exerted on the current sumo association is limited. ${ }^{22} \mathrm{~A}$ second possibility is

\footnotetext{
${ }^{21}$ Nonlinearities of this sort have been shown to distort behavior in many other contexts as well, including Robert Topel (1983) and Judith Chevalier and Glenn Ellison (1997).

${ }^{22}$ It is worth noting that the popularity of sumo wrestling has declined substantially over the last two decades, suggesting that other forms of recreation are substitutes.
} 
that the nonlinear payoff structure generates interest in otherwise unimportant matches on the final days of the tournament. For the same reason that wrestlers want to rig the matches on the bubble, the fans are interested in the outcome.

\section{REFERENCES}

Becker, Gary S. and Stigler, George J. "Law Enforcement, Malfeasance, and the Compensation of Enforcers." Journal of Legal Studies, January 1974, 3(1), pp. 1-19.

Chevalier, Judith and Ellison, Glenn. "RiskTaking by Mutual Funds as a Response to Incentives." Journal of Political Economy, December 1997, 105(6), pp. 1167-200.

DiTella, Rafael and Schargrodsky, Ernesto. "The Role of Wages and Auditing during a Crackdown on Corruption in the City of Buenos Aires." Mimeo, Harvard Business School, 2000.

Duggan, Mark and Levitt, Steven. "Winning Isn't Everything: Corruption in Sumo Wrestling." National Bureau of Economic Research (Cambridge, MA) Working Paper No. 7798, 2001.

Fisman, Ray. "Estimating the Value of Political Connections." American Economic Review, September 2001, 91(4), pp. 1095-102.

Fudenberg, Drew and Tirole, Jean. Game theory. Cambridge, MA: MIT Press, 1991.

Hall, Mina. The big book of sumo. Berkeley, CA: Stonebridge Press, 1997.

Itai, Keisuke. Nakabon. Tokyo: Shogakkan Press, 2000.
Leff, Nathaniel. "Economic Development through Bureaucratic Corruption." American Behavioral Scientist, November 1964, 8(3), pp. 8-14.

Mauro, Paulo. "Corruption and Growth.” Quarterly Journal of Economics, August 1995, 110(2), pp. 681-711.

McAfee, R. Preston. "Bidding Rings." American Economic Review, June 1992, 82(3), pp. 579-99.

Onaruto. Yaocho. Tokyo: Line Books, 2000.

Porter, Robert H. and Zona, J. Douglas. "Detection of Bid Rigging in Procurement Auctions." Journal of Political Economy, June 1993, 101(3), pp. 518-38.

Shleifer, Andrei and Vishny, Robert W. "Corruption." Quarterly Journal of Economics, August 1993, 108(3), pp. 599-617.

Shukan Post. Shukan Post-wa Yaocho-wo Ko Hojite Kita. Tokyo: Shogakkan Bunko, 2000.

Stigler, Stephen. The history of statistics: The measurement of uncertainty before 1900. Cambridge, MA: Harvard University Press, 1986.

Topel, Robert. "On Layoffs and Unemployment Insurance." American Economic Review, September 1983, 73(4), pp. 541-59.

Transparency International. "Corruption Perceptions Index Press Release." Berlin, Germany, September 13, 2000.

West, Mark. "Legal Rules and Social Norms in Japan's Secret World of Sumo." Journal of Legal Studies, January 1997, 26(1), pp. 165201. 